\title{
Stage IIIA Cervical Cancer AJCC v6 and v7
}

National Cancer Institute

\section{Source}

National Cancer Institute. Stage IIIA Cervical Cancer A/CC v6 and v7. NCI Thesaurus.

Code C6322.

Stage IIIA includes: T3a, N0, M0. T3a: Tumor involves lower third of vagina, no extension to pelvic wall. NO: No regional lymph node metastasis. MO: No distant metastasis. (AJCC 6th and 7th eds.) 